\title{
Evaluation of Exposure to Chemical Substances through Foods -Exposure to Pesticides, Heavy Metals, Dioxins, Acrylamide and Food Additives in Japan-
}

\author{
Tamio Maitani* \\ Division of Foods, National Institute of Health Sciences, Kamiyoga 1-18-1, Setagaya, Tokyo 158-8501, Japan
}

(Received February 4, 2004)

\begin{abstract}
For the risk management of chemical substances in foods, evaluating the exposure to chemical substances is essential. The Ministry of Health, Labour and Welfare (MHLW) continuously performs total diet studies to estimate the average Japanese dietary intake of various chemical substances, such as pesticides, heavy metals, dioxins, food additives, etc. In many of the studies, the National Institute of Health Sciences, especially the Division of Foods plays a central role. In this mini-review, the results of several recent total diet studies are described. The Total Diet Study of Food Contaminants which began in 1977 has found that the intake of banned pesticides is very low compared with the acceptable daily intake (ADI). However, the dietary intake of $\mathrm{Cd}$ is high, and was $52 \%$ of the Provisional Tolerable Weekly Intake in 2002. The average daily intake of dioxins [polychlorinated dibenzo- $p$-dioxins (PCDDs), polychlorinated dibenzofurans (PCDFs) and coplanar-polychlorinated biphenyls (PCBs)] was 1.49 pgTEQ/ $\mathrm{kg}$ in 2002, which is lower than the tolerable daily intake (TDI) value of $4 \mathrm{pgTEQ} / \mathrm{kg} / \mathrm{day}$. Total diet study samples from the Kansai area demonstrated a reduction in dioxin intake between 1977 and 2002. The daily dietary intake of acrylamide was estimated to be several scores of micrograms per person. Although the daily intake of most food additives was much lower than ADI, the intake of nitrate exceeded ADI when estimated by the market basket method. The contribution of food additives was low and most of the intake was attributed to nitrate in vegetables. These data form the basis for risk management performed by the MHLW.
\end{abstract}

Key words — daily intake, pesticide, heavy metal, dioxin, acrylamide, total diet study

\section{INTRODUCTION}

Japan's Ministry of Health, Labour and Welfare (MHLW) continuously performs many total diet studies to estimate the Japanese daily dietary intake of food contaminants and food additives. These results are used as basal data for risk management by the MHLW. The National Institute of Health Sciences (NIHS) plays a central role in most of these studies. In this paper, the results of several total diet studies are described to illustrate the exposure levels of the average Japanese person to food contaminants and food additives.

*To whom correspondence should be addressed: Division of Foods, National Institute of Health Sciences, Kamiyoga 1-181, Setagaya, Tokyo 158-8501, Japan. Tel.: +81-3-3700-2158; Fax: +81-3-3700-9348; E-mail: maitani@nihs.go.jp

\section{METHODS OF TOTAL DIET STUDY}

For the MHLW study, foods are classified into fourteen groups: I; rice and rice products, II; cereal grains, nuts and seeds, potatoes, III; sugar and confectioneries, IV; fats and oils, V; bean and bean products, VI; fruits, VII; green vegetables, VIII; other vegetables, mushrooms and seaweeds, IX; seasonings and beverages, $\mathrm{X}$; fish and shellfish, $\mathrm{XI}$; meat and eggs, XII; milk and dairy products, XIII; other cooked meals, XIV; drinking water.

Each food sample is selected from foods adopted in the National Nutrition Survey conducted by the MHLW. Usually, each institution collects 100 to 200 food samples and these are cooked, if necessary. The classified samples are combined in proportion to the average Japanese intake of foodstuff estimated by the National Nutrition Survey, and are homogenized 


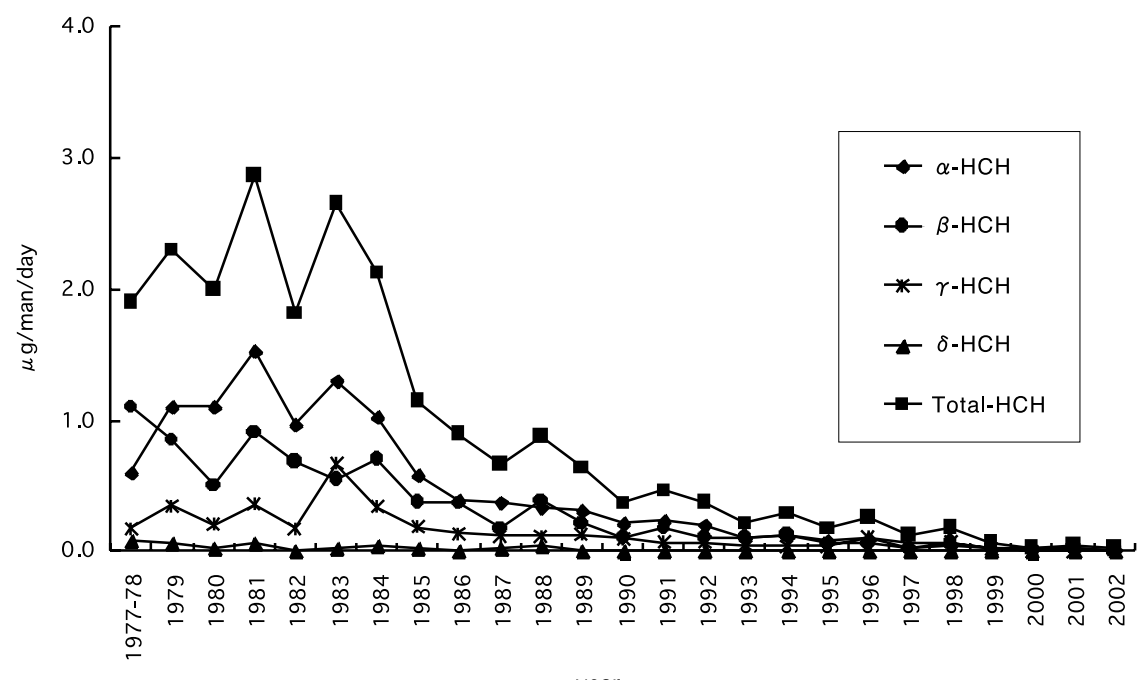

Fig. 1. Time Trend of the Dietary Daily Intake of $\mathrm{HCH}$ by the Average Japanese Person

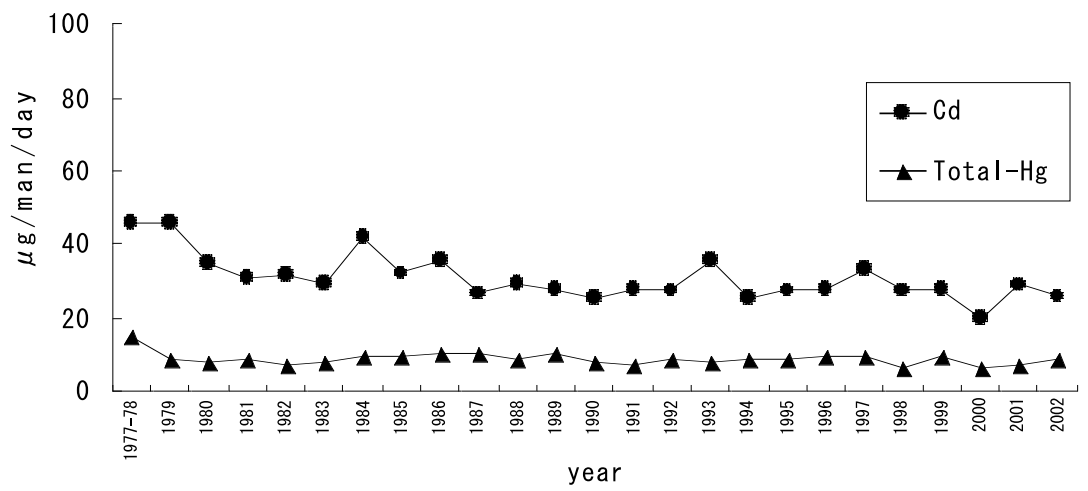

Fig. 2. Time Trend of the Dietary Daily Intake of $\mathrm{Cd}$ and Total-Hg by the Average Japanese Person

and preserved at $-20^{\circ} \mathrm{C}$ until analysis. The results for fourteen respective food groups are summed to determine the total daily intake.

\section{THE TOTAL DIET STUDY OF FOOD CONTAMINANTS (ESTIMATION OF DAILY DIETARY INTAKE OF FOOD CONTAMINANTS)}

This project is the total diet study of fourteen pesticides and metabolites $(\alpha-\mathrm{HCH}, \beta-\mathrm{HCH}, \gamma-\mathrm{HCH}$, $\delta$-HCH, $p, p^{\prime}$-DDT, $p, p^{\prime}$-DDE, $p, p^{\prime}$-DDD, $o, p$ '-DDT, dieldrin, heptachlor epoxide, hexachlorobenzene, malathion, fenitrothion and diazinon), seven metals $(\mathrm{Pb}, \mathrm{Cd}$, total- $\mathrm{Hg}$, total-As, $\mathrm{Cu}, \mathrm{Mn}, \mathrm{Zn})$ and total polychlorinated biphenyl (PCB). Mercury or arsenic is determined as the whole of a metal regardless of its chemical forms. This project started in 1977 and has been performed so far in cooperation with a total of eighteen local government institutes.

The data form the bases of the risk management performed by the MHLW. Figure 1 shows the time trend of $\mathrm{HCH}$ intake in Japan. ${ }^{1)}$ Since the use of $\mathrm{HCH}$ was banned in 1971, its intake declined during the 1980s and for the past three years has been 0.03$0.05 \mu \mathrm{g}$.

Figure 2 represents the time trend of the dietary intake of $\mathrm{Cd}$ and $\mathrm{Hg} .{ }^{1)} \mathrm{A}$ considerable amount of $\mathrm{Cd}$ is taken even now: in 2002, the average daily intake was $26 \mu \mathrm{g}$. This corresponds to $52 \%$ of the tolerable daily intake (TDI) calculated based on the Provisional Tolerable Weekly Intake (PTWI) of $7 \mu \mathrm{g} / \mathrm{kg}$ established by the JECFA (FAO/WHO Joint Expert Committee on Food Additives) and the average body weight of a Japanese $(50 \mathrm{~kg})$. Among the fourteen food groups, Group I (rice and rice products) accounts for $41 \%$ of the total intake. The results of 
Table 1. Ratios of Average Intake of Respective Contaminants to the ADIs

\begin{tabular}{lcccc}
\hline \hline Compound & ADI & \multicolumn{2}{c}{ Average intake } & Ratio of intake to ADI \\
\cline { 2 - 4 } & $\mu \mathrm{g} / \mathrm{kg} /$ day & $\mu \mathrm{g} / \mathrm{man} /$ day & $\mu \mathrm{g} / \mathrm{kg} /$ day $\left.{ }^{d}\right)$ & 0.005 \\
\hline Total-HCH & 12.5 & 0.033 & 0.0007 & 0.110 \\
Total-DDT & 5 & 0.275 & 0.006 & 0.580 \\
Dieldrin & 0.1 & 0.029 & 0.0006 & 0.420 \\
Heptachlor epoxide & $0.1^{a)}$ & 0.021 & 0.00042 & 0.222 \\
PCB & $5^{b}$ & 0.554 & 0.011 & 0.1 \\
Malathion & 20 & 1.0 & 0.0 & 0.0 \\
Fenitrothion & 5 & 0.1 & 0.0 & 0.0 \\
Diazinon & 2 & 0.0 & 0.0 & 11.7 \\
Pb & $3.6^{c)}$ & 21 & 0.42 & 52.0 \\
Cd & $1^{c)}$ & 26 & 0.52 & 25.4 \\
Total-Hg & $0.71^{c)}$ & 9 & 0.18 & 4.6 \\
$\mathrm{Cu}$ & $500^{c)}$ & 1150 & 23 & \\
\hline
\end{tabular}

ADI: Unmarked, acceptable daily intake set by the MHLW; $a$ ) PTDI set by the JMPR. $b$ ) PTDI set by the MHLW.

c) Calculated from PTWI set by the JECFA. $d$ ) Body weight $=50 \mathrm{~kg}$.

this Total Diet Study of Food Contaminants were sent to the WHO as being the exposure of an average Japanese.

In Table 1, the ratios of the average intake of respective contaminants to their ADIs are summarized.

The JECFA sets the PTWI for As as inorganic As. Therefore, the development of an analytical method for inorganic As in food is now in progress as a separate project. Furthermore, the PTWI for $\mathrm{Hg}$ is set as total $\mathrm{Hg}$ and methyl mercury. An analytical method for methyl mercury applicable to the Total Diet Study should be established.

\section{TOTAL DIET STUDY FOR DIOXINS}

In the Action Plan to promote food safety, the MHLW expresses its policy about dioxins in foods and states that the health effects should be assessed by comparing the total amount of dioxins taken through foods (average daily intake) with the TDI of the dioxins (http://www.mhlw.go.jp/topics/0101/ tp0118-1.html\#no13).

We found the average daily intake of dioxins [polychlorinated dibenzo- $p$-dioxins (PCDDs), polychlorinated dibenzofurans (PCDFs) and coplanar$\mathrm{PCBs}$ ] to be $1.49 \mathrm{pgTEQ} / \mathrm{kg}$ b.w./day in 2002. This is lower than the TDI of $4 \mathrm{pgTEQ} / \mathrm{kg} /$ day. The average daily intake of dioxin (PCDD/Fs) was $0.52 \mathrm{pgTEQ} / \mathrm{kg} / \mathrm{day}$ and that of Co-PCBs was $0.97 \mathrm{pgTEQ} / \mathrm{kg} / \mathrm{day}$. The intake of dioxins in 2000 and 2001 was 1.45 and $1.63 \mathrm{pgTEQ} / \mathrm{kg} / \mathrm{day}$, respec-

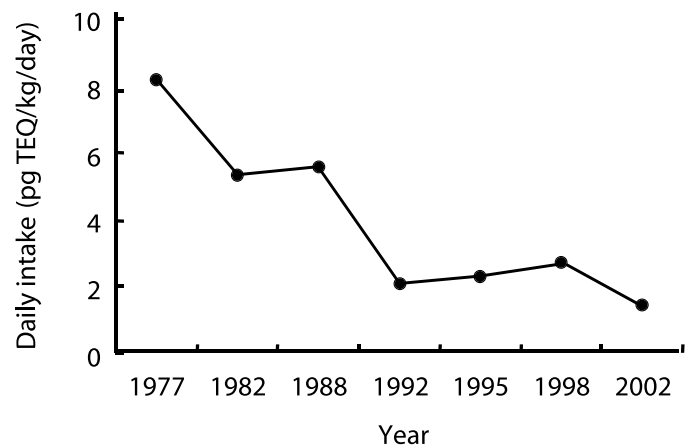

Fig. 3. Time Trend of the Dietary Daily Intake of Dioxins in the Kansai Area

tively; thus, the daily intake has remained almost constant at $1.5 \mathrm{pgTEQ} / \mathrm{kg} /$ day during the last three years. However, analytical results of total diet study samples from the Kansai area, ${ }^{2)}$ which had been conserved by the NIHS until the time of analysis, demonstrated that the average daily intake of dioxins decreased between 1977 and 2002 as shown in Fig. 3, when several important measures were taken to decrease dioxin pollution.

Apart from the total diet study, we applied the guideline methods established by the MHLW to various foods, ${ }^{3-5)}$ and also improved them. ${ }^{6-9)}$ The analysis of dioxins with HRGC/HRMS is a long process. Therefore, screening methods are necessary. We are also investigating several screening methods for dioxins including the CALUX method, ${ }^{10)}$ and are studying the possible effects of vegetable constituents on decreasing the health risk of dioxins. ${ }^{11)}$ 


\section{PESTICIDES}

Apart from the Total Diet Study of Food Contaminants, the MHLW has been performing total diet studies on various pesticides based on the market basket method. For many pesticides, the daily intake was below the detection limit (not detected, N.D.). The daily intake of no pesticide was over the ADI. Compared with the ADI, the intake of bromine was exceptionally high at $12.08-16.30 \%$ of its ADI.

\section{ACRYLAMIDE}

In April, 2002, the Swedish government announced that a high concentration of acrylamide was present in potato chips, French fried potatoes, etc. Immediately after this warning, we started to analyze the acrylamide content in foods in Japan, devising a $\mathrm{GC} / \mathrm{MS}^{12)}$ and an $\mathrm{LC} / \mathrm{MS}^{13)}$ method to make this analysis. Using these methods, the acrylamide concentration in foods commercially available in Japan was analyzed.

The concentrations are officially announced on the home page of the MHLW (http://www.mhlw.go. jp/topics/2002/11/tp1101-1.html). The calculated daily intake was several scores of micrograms per person. The human health effect of acrylamide in food has not been clearly elucidated. Therefore, food authorities of various countries and international organizations only recommend not having an unbalanced diet biased toward high-acrylamide content foods.

Thus, the elucidation of human health effects is the most important subject in the risk analysis of acrylamide.

\section{FOOD ADDITIVES}

Food additives are chemical substances intentionally added for a definite purpose; therefore, their intake should be kept within safe limits. There are several methods available for estimating the daily intake of food additives, each having good and bad attributes. In recent years, the market basket method, a method based on a questionnaire survey of the amount of produced additives and a method based on the results of official inspections have been used officially. Although previous investigations were restricted to only chemically synthesized additives, the daily intake of natural food additives (existing food additives) has also been partly estimated in recent years. The results showed that the daily intake of most food additives was much lower than their ADI values. However, the intake of nitrate exceeded the ADI when estimated by the market basket method. For example, the daily intake in 1998 to 1999 was $190 \mathrm{mg}$, which corresponds to $103 \%$ of the ADI. However, most of the intake is due to nitrate taken from vegetables, and the contribution from food additives is small. In fiscal 2003, a total diet study of nitrate was conducted again to ascertain the origin of the nitrate.

\section{FOOD CONTAMINATION MONITORING PROGRAM}

Beside total diet studies, the contaminants in foods are monitored by institutes of most local governments in the Monitoring Program of Food Contamination, which started in 1971. Under this program, the analytical results of contaminants in foods determined by local governments are reported to the NIHS and summarized. In 2001, 200000 pieces of data were reported from 45 local government institutes. The data were partly sent to the WHO as a part of an international survey. Thus, about three million pieces of data have been stored in the NIHS database.

\section{CLOSING}

As mentioned above, many total diet studies and the Monitoring Program of Food Contamination have been continuously performed to evaluate the dietary intake of food contaminants and food additives in Japan. The Division of Foods (NIHS) has taken a leading role in cooperation with the institutes of many local governments. We intend to continue with these programs as part of the risk management performed at the MHLW.

Acknowledgements Most of this minireview is based on work accomplished by the staff of the Division of Foods (NIHS), local government institutes and laboratories designated by the MHLW. The author is grateful for their cooperation. 


\section{REFERENCES}

1) Toyoda, M., Sasaki, K., Matsuda, R. and Ikarashi, A. (2000) Total Diet Survey in Japan 1977 1999 Estimation of daily dietary intake of food contaminants -, Division of Foods, National Institute of Health Sciences, Tokyo.

2) Toyoda, M., Uchibe, H., Yanagi, T., Kono, Y., Hori, T. and IIda, T. (1999) Decreased daily intake of PCDDs, PCDFs and Co-PCBs from foods in Japan from 1977 to 1998. J. Food Hyg. Soc. Japan, 40, 494-499.

3) Amakura, Y., Tsutsumi, T., Sasaki, K. and Maitani, T. (2003) Levels and congener distribution of PCDDs, PCDFs and Co-PCBs in Japanese retail fresh and frozen vegetables. J. Food Hyg. Soc. Japan, 44, 294-302.

4) Amakura, Y., Tsutsumi, T., Sasaki, K. and Maitani, T. (2003) Contamination levels and congener distribution of PCDDs, PCDFs and Co-PCBs in several fast foods in Japan. J. Food Hyg. Soc. Japan, 44, 316-320.

5) Tsutsumi, T., Amakura, Y., Yanagi, T., Nakamura, M., Kono, Y., Uchibe, H., Iida, T., Toyoda, M., Sasaki, K. and Maitani, T. (2003) Levels of PCDDs, PCDFs and dioxin-like PCBs in retail fish and shellfish in Japan. Organohalogen Compounds, 62, 93-96.

6) Tsutsumi, T., Amakura, Y., Sasaki, K., Toyoda, M. and Maitani, T. (2003) Evaluation of an aqueous $\mathrm{KOH}$ digestion followed by hexane extraction for analysis of PCDD/Fs and dioxin-like PCBs in retailed fish. Anal. Bioanal. Chem., 375, 792-798.

7) Amakura, Y., Tsutsumi, T., Sasaki, K., Toyoda M. and Maitani, T. (2003) Cleanup of food samples with pre-packed multi-layer silica gel column for the analysis of PCDDs, PCDFs and dioxin-like PCBs. J. Food Hyg. Soc. Japan, 44, 119-125.

8) Amakura, Y., Tsutsumi, T., Sasaki, K., Toyoda, M. and Maitani, T. (2002) Comparison of sulfuric acid treatment and multi-layer silica gel column chromatography in cleanup methods for determination of PCDDs, PCDFs and dioxin-like PCBs in foods. J. Food Hyg. Soc. Japan, 43, 312-321.

9) Amakura, Y., Tsutsumi, T., Sasaki, K. and Maitani, T. (2003) Modification of cleanup methods for dioxin analysis in green leafy vegetables and comparison of packing methods for a multi-layer silica gel column. J. Food Hyg. Soc. Japan, 44, 321327.

10) Tsutsumi, T., Amakura, Y., Nakamura, M., Brown, D. J., Clark, G. C., Sasaki, K., Toyoda, M. and Maitani, T. (2003) Validation of the CALUX bioassay for the screening of PCDD/Fs and dioxin-like PCBs in retail fish. Analyst, 128, 486-492.

11) Amakura, Y., Tsutsumi, T., Nakamura, M., Kitagawa, H., Fujino, J., Sasaki, K., Toyoda, M., Yoshida, T. and Maitani, T. (2003) Activation of the aryl hydrocarbon receptors by some vegetable constituents determined using in vitro receptor gene assay. Biol. Pharm. Bull., 26, 532-539.

12) Takatsuki, S., Nemoto, S., Sasaki, K. and Maitani, T. (2003) Determination of acrylamide in processed foods by LC/MS using column switching. J. Food Hyg. Soc. Japan, 44, 89-95.

13) Nemoto, S., Takatsuki, S., Sasaki, K. and Maitani, T. (2002) Determination of acrylamide in foods by GC/MS using ${ }^{13} \mathrm{C}$-labeled acrylamide as an internal standard. J. Food Hyg. Soc. Japan, 43, 371-376. 